\title{
PROPERTY OF GROWTH DETERMINED BY SPECTRUM OF OPERATOR ASSOCIATED WITH THE TIMOSHENKO SYSTEM WITH WEAKLY DISSIPATION
}

\author{
C.A. Raposo, J.E.M. Rivera And R.R. Alves
}

Abstract. In this work, we consider the Timoshenko system with weakly dissipation, one dissipation, $\varphi_{t}$, on the transverse displacement and another $\psi_{t}$, on the rotation angle of a filament of the beam

$$
\begin{gathered}
\rho_{1} \varphi_{t t}-\kappa\left(\varphi_{x}+\psi\right)_{x}+\varphi_{t}=0, \text { in }(0, L) \times(0, t), \\
\rho_{2} \psi_{t t}-b \psi_{x x}+\kappa\left(\varphi_{x}+\psi\right)+\psi_{t}=0, \text { in }(0, L) \times(0, t),
\end{gathered}
$$

with initial conditions

$$
\varphi(x, 0)=\varphi_{0}(x), \varphi_{t}(x, 0)=\varphi_{1}(x), \psi(x, 0)=\psi_{0}(x), \psi_{t}(x, 0)=\psi_{1}(x) .
$$

In [13] was proved the exponential stability of the semigroup associated with this system, and now we prove the property of growth determined by spectrum of operator associated, present the type of semigroup and also indicate the best constant for the exponential stability.

Mathematics subject classification (2010): 35B35, 35B40, 35L50.

Keywords and phrases: Timoshenko, $C_{0}$-semigroup, spectrum, property of growth, stability.

\section{REFERENCES}

[1] R. A. Adams, Sobolev Spaces, Academic Press, New York, 1975.

[2] Y. S. S. AyAla, Global existence and exponential stability for a Timoshenko beam model, International Journal of Applied Science and Technology, 3 , 7 (2013), 141-150.

[3] M. Bass ama, D. Mercier, S. Nicaise, A. Wehbe, Polynomial stability of the Timoshenko system by one boundary damping, J. Math. Anal. Appl., 425 (2015), 1177-1203.

[4] F. DELlORO, V. PATA, Lack of exponential stability in Timoshenko systems with flat memory kernels, Applied Mathematics and Optimization, 71, (2015), 79-93.

[5] Z. J. HAN, G. Q. XU, Exponential stability of Timoshenko beam system with delay terms in boundary feedbacks, ESAIM Control Optim. Calc. Var., 17, (2011), 552-574.

[6] F. L. HuAnG, Characteristic condition for exponential stability of linear dynamical systems in Hilbert spaces, Ann. of Diff. Eqs., 1, 1 (1985), 43-56.

[7] M. Kirane, B. SAid-Houari, M. N. Anwar, Stability result for the Timoshenko system with a time-varying delay term in the internal feedbacks, Commun. Pure Appl. Anal., 10, 2 (2011), 667-686.

[8] K. LIU, Z. LIU, On the type of $C_{0}$-semigroups associated with the abstract linear viscoelastic system, Z. Angew. Math. Phys., 47, 1 (1996), 1-15.

[9] Z. LIU, S. Zheng, Semigroups associated with dissipative systems, Chapman \& Hall/CRC, 1999.

[10] Z. MA, L. Zhang, X. YAng, Exponential stability for a Timoshenko-type system with history, J. Math. Anal. Appl., 380, (2011), 299-312.

[11] A. PAZY, Semigroup of linear operators and applications to partial differential equations, SpringerVerlag, New York, 1983.

[12] J. PRÜSS, On the Spectrum of $C_{0}$-Semigroups, Transaction of the American Mathematical Society, 284, 2 (1984), 847-857.

[13] C. A. Raposo, J. Ferreira, M. L. Santos, N. N. Castro, Exponential Stability for the Timoshenko System with two weak Dampings, Applied Mathematics Letters, 18, 5 (2005), 535-541. 
[14] M. Renardy, On the type of certain $C_{0}$-semigroups, Comm. Part. Diff Eq., 18, (1993), 1299-1307.

[15] J.E.M. Rivera, R. RACKE, Timoshenko systems with indefinite damping, J. Math. Anal. Appl., 341, (2008), 1068-1083.

[16] D. H. SHI, D. X. Feng, Exponential decay of Timoshenko Beam with locally distributed feedback, Proceeding of the 99'IFAC World Congress, Beijing, F.

[17] A. Soufyane, Exponential stability of the linearized nonuniform Timoshenko beam, Nonlinear Analysis: Real World Applications, 10 , (2009), 1016-1020.

[18] A. WyLER, Stability of wave equations with dissipative boundary condition in a bounded domain, Differential and Integral Equations, 7, 2 (1994), 345-366. 